\title{
FUTURE ENERGY BENCHMARK FOR DESALINATION: IS IT BETTER TO HAVE A POWER (ELECTRICITY) PLANT WITH RO OR MED/MSF?
}

\author{
MUHAMMAD WAKIL SHAHZAD \\ Water Desalination and Reuse Centre, \\ King Abdullah University of Science \& Technology, \\ Thuwal, 23955-6900, Saudi Arabia \\ Muhammad.shahzad@kaust.edu.sa \\ KIM CHOON NG \\ Water Desalination and Reuse Centre, \\ King Abdullah University of Science \& Technology, \\ Thuwal, 23955-6900, Saudi Arabia. \\ Kim.ng@kaust.edu.sa \\ KYAW THU \\ Mechanical Engineering Department, \\ National University of Singapore, Singapore \\ mpekyaw@nus.edu.sg
}

Published 22 June 2016

\begin{abstract}
Power and desalination cogeneration plants are common in many water scared courtiers. Designers and planners for cogeneration face tough challenges in deciding the options:- Is it better to operate a power plant (PP) with the reverse osmosis (i.e., PP+RO) or the thermally-driven multi-effect distillation/multi-stage flashed (PP+MED/MSF) methods. From literature, the RO methods are known to be energy efficient whilst the MED/MSF are known to have excellent thermodynamic synergies as only low pressure and temperature steam are used. Not with-standing the challenges of severe feed seawater of the Gulf, such as the frequent harmful algae blooms (HABs) and high silt contents, this presentation presents a quantitative analyses using the exergy and energetic approaches in evaluating the performances of a real cogeneration plant that was recently proposed in the eastern part of Saudi Arabia. We demonstrate that the process choice of $\mathrm{PP}+\mathrm{RO}$ versus $\mathrm{PP}+\mathrm{MED}$ depends on the inherent efficiencies of individual process method which is closely related to innovative process design. In this connection, a method of primary fuel cost apportionment for a co-generation plant with a MED desalination is presented. We show that an energy approach, that captures the quality of expanding steam, is a better method over the conventional work output (energetic) and the energy method seems to be over-penalizing a thermally-driven MED by as much as $22 \%$ in the operating cost of water.
\end{abstract}

Keywords: Co-generation system; hybrid cycles; desalination economic; energetic and exergetic analysis; desalination carbon footprint.

This is an Open Access article published by World Scientific Publishing Company. It is distributed under the terms of the Creative Commons Attribution 3.0 (CC-BY) License. Further distribution of this work is permitted, provided the original work is properly cited. 


\section{Introduction}

China is $20 \%$ of the world's population, but only has $7 \%$ of freshwater reserves. As 'the world's factory', China is one of the highest consumers and emitters of industrial raw materials. Recent survey shows that major rivers (19\%) and key lakes (36\%) are severely polluted and are unusable as a source for water supply. In the Yangtze and Songhua rivers basin alone, 107 kinds of toxic and hazardous organic pollutants have been detected. It is estimated that in 2030 net water demand will grow up to 818 billion cubic meters compared to 618 billion cubic meters in 2010. Of this 2030 net water demand, agriculture, industry and domestic utilization is estimated as $50 \%, 32 \%$ and $18 \%$ respectively. There will be deficiency of 199 billion cubic meters, about 24\% demandsupply gap by 2030 as shown in Figure 1. Chinese government allocated RMB 4 trillion for water infrastructure improvement in 2011-2020

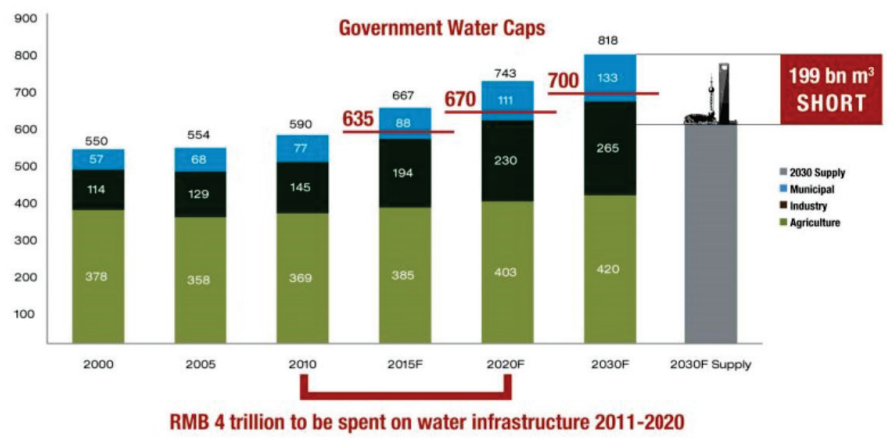

Fig. 1. Water supply-demand gap in China from 2000-2030.

Most of China cities $(\geq 60 \%)$ are under extreme water scarcity, less than $500 \mathrm{~m} 3 /$ capita/year water available from all sources as shown in Figure 2. In China, there are 57 desalination plants operating presently with different capacities. In the past, Reverse Osmosis (RO) technology was the dominant technology applied in China desalination industry but in 2008 the biggest Multi-Effect Distillation (MED) plant (200,000 m3/day) was installed combined with Tianjin Beijiang Power Plant ${ }^{4}$.

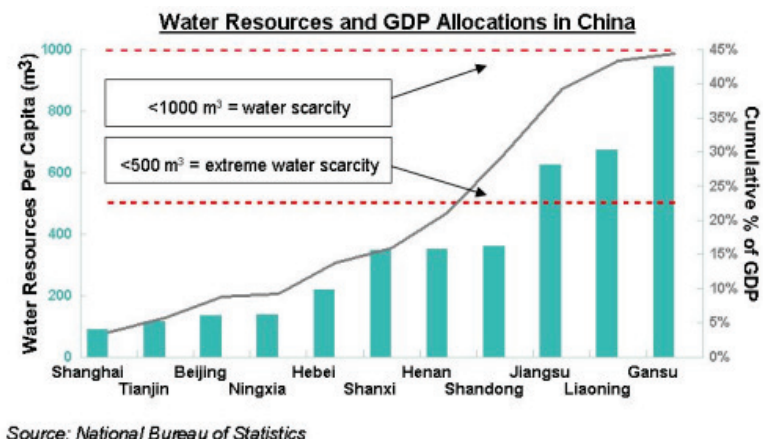

Fig. 2. Water scarcity level in different cities of China. 
The Chinese government has set ambitious targets to boost desalination capacity from today's modest 800,000 tons to 3 million tons a day by 2020 and this fast expanding desalination industry would consume more energy than China's total installed electricity capacity in 2012 , about $1200 \mathrm{GW}^{5}$.

Desalination is an energy intensive process with significant environmental costs. Desalination not only emits carbon to environment but also highly concentrated brine back to sea. This has increased the temperature and salinity of sea, with the latter rising by around 2 percent over the last 20 years, with a negative impact on marine life and ecosystems. The increasing salinity makes future desalination even more difficult. There is a need to investigate the best-match for power plant (PP) \& desalination systems for energy efficiency to reduce the specific energy consumption in terms of $\mathrm{kWh} / \mathrm{m}^{3}$ and carbon emission. Hence, this is the motivation to find efficient power and desalination system combination.

\section{Power + Desalination: Best Match}

Efficient power and desalination cogeneration system analysis is conducted using real data of a cogeneration system. Exergy approach is used to apportion primary fuel cost to power and desalination systems. Two cases were analyzed; power plant $(\mathrm{PP})+$ reverse osmosis (RO) system and power plant (PP) + multi-effect desalination (MED) system as shown in Figure 3.

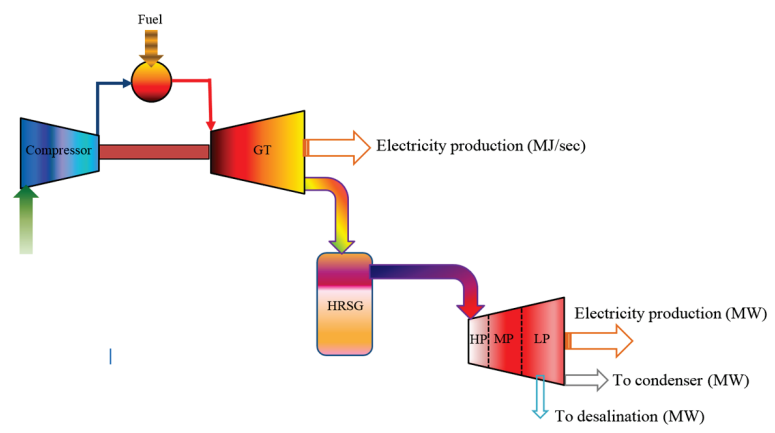

Fig. 3. Power + Desalination cogeneration system configuration.

Figure 4 summarized cogeneration system selection. It can be seen that for a specific water production $\left(2813 \mathrm{~m}^{3} / \mathrm{hr}\right)$ the $\mathrm{PP}+\mathrm{RO}$ plants are efficient than $\mathrm{PP}+\mathrm{MED}(\mathrm{GOR} \leq 20)$ system. Efficiency of whole system is depends on individual systems performance. $\mathrm{PP}+\mathrm{MED}$ can be more efficient approach only if MED system GOR can be increased more than 20 . $P P+M E D(G O R \geq 20)$ will not be only efficient approach but also help to prevent hazards algae blooms those are frequently occurring in some region in the world and dangerous for health. 


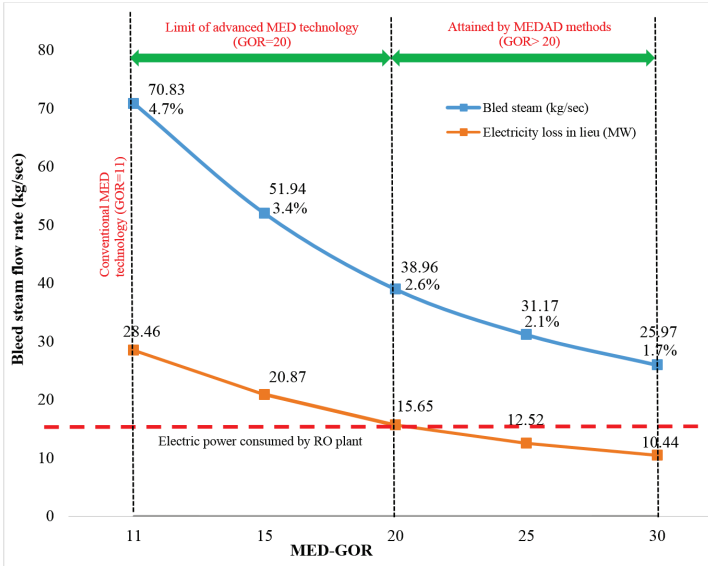

Fig. 4. Cogeneration systems ( $\mathrm{PP}+\mathrm{RO} / \mathrm{PP}+\mathrm{MED})$ comparison at different MED GOR for $2813 \mathrm{~m}^{3} / \mathrm{hr}$ water production.

Now the question is, whether MED GOR can be $\geq 20$ ? The conventional MED GOR is limited to 10-11 and advanced MED (with vapor re-circulation) GOR can be up to 20 . This GOR is limited due to operational limitations namely; top brine temperature, TBT (typically $70^{\circ} \mathrm{C}$ ) and bottom brine temperature, BBT (typically $40^{\circ} \mathrm{C}$ ) of MED system. Conventional or advanced MED systems with power plants cannot beat $\mathrm{PP}+\mathrm{RO}$ in terms of energy efficiency.

We proposed hybrid MED+AD cycle to overcome conventional MED limitations and hybrid MED+AD system GOR can be more then 20. In this hybrid system multi-effect desalination system is integrated with adsorption cycle to overcome BBT limitations and now MED last stage temperature can be as low as $8-10^{\circ} \mathrm{C}$. This hybridization will not only improve water production (2-3 folds) but also reduce corrosion and fouling chances due to low operational temperature.

\section{Experimentation and Results Discussion}

A three-stage MED system and an AD cycle detail can be found in the literature ${ }^{6-15}$. Figure 5 shows the temperature profiles of conventional MED stages and hybrid MEDAD stages at heat source $50^{\circ} \mathrm{C}$. Initially system was started as a conventionally MED and it can be seen that inter-stage temperature difference $(\mathrm{dT})$ is about $1{ }^{\circ} \mathrm{C}$. After stable results, MED was linked with $\mathrm{AD}$ and it can be seen that adsorbent pulled last stage temperature to about $30^{\circ} \mathrm{C}$ and inter-stage temperature difference increased to 4$5^{\circ} \mathrm{C}$. This higher inter-stage dT increase heat flux and evaporation rate in each stage. 


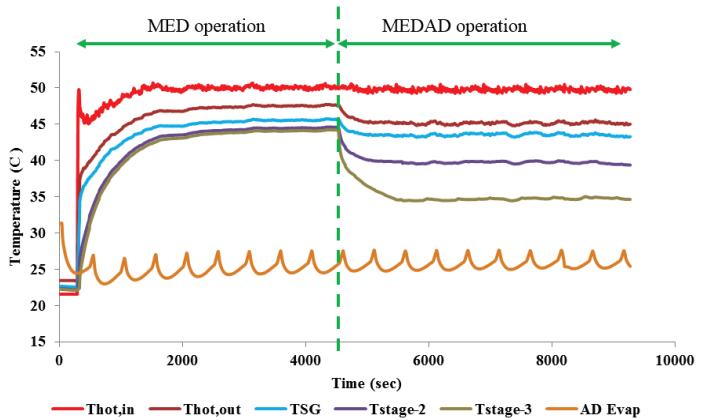

Fig. 5. Temperature profile of MEDAD components at heat source $50^{\circ} \mathrm{C}$.

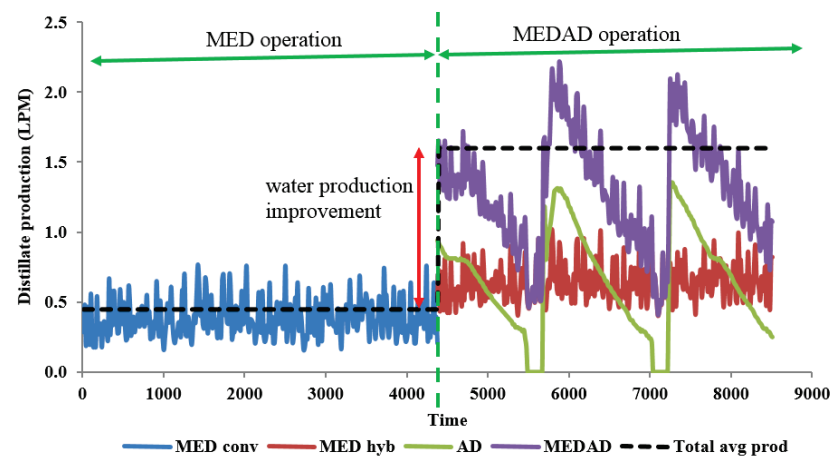

Fig. 6. Distillate production from MED and MEDAD at heat source $50^{\circ} \mathrm{C}$.

The last stage temperature is $30^{\circ} \mathrm{C}$ is because our system has only three stages. In real plant it can be as low as $10^{\circ} \mathrm{C}$ and practically 8-10 stages can be inserted with same top brine temperature. This higher operational range is only possible by $\mathrm{AD}$ hybridization to the last stage of MED.

Figure 6 shows the water production profile of conventional MED and hybrid MEDAD cycle at heat source $50^{\circ} \mathrm{C}$. It can be seen clearly that once MED is linked with $\mathrm{AD}$, water production boosted 2-3 times, GOR increased more than 20.

\section{Desalination Systems Economic Analysis}

On the basis of above analysis for primary fuel cost and with data from the published literature $^{16,17}$ the life-cycle cost (LCC) of water production is compared for all capital expenditure (Capex) and operation expenditure (Opex), across all proven industrial processes, as shown in Figure 7. Exergy factor calculated above is utilized only for thermal and electricity cost calculations. Energy based analysis has good agreement with $\mathrm{GWI}^{17}$ data. 


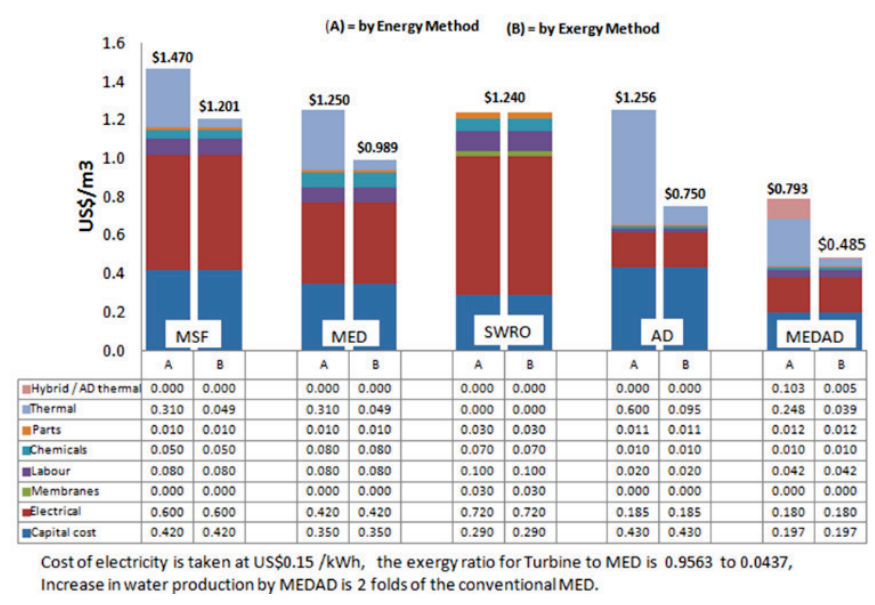

Fig. 7. Desalination methods costing by energetic and exergetic approach.

\section{Conclusions}

An efficient cogeneration (power+desalination) system is investigated and it is found that $\mathrm{PP}+\mathrm{RO}$ can be an efficient approach if MED GOR is less than 20. An innovative hybrid desalination cycle called MEDAD is investigated experimentally that can achieve GOR more than 20. Hybrid MEDAD+PP can beat PP+RO system in terms of energy efficiency and it is also environment friendly. MEDAD $+\mathrm{PP}$ are the only system achieving a lowest life-cycle cost (LCC) of US $\$ 0.5 / \mathrm{m}^{3}$.

\section{References}

1. http://www.theguardian.com/sustainable-business/china-water-choices

2. https://www.chinadialogue.net/article/show/single/en/7839-Who-is-responsible-for-China-swater-?gclid=CKHUiKa968UCFYrKtAodYHoASw

3. http://chinawaterrisk.org/big-picture/2030-demand-supply/

4. http://www.waterworld.com/articles/wwi/print/volume-25/issue-6/regional-spotlight-asiapacific/market-report-developing-desalination.html.

5. http://www.thethirdpole.net/chinas-desalination-plans-could-thwart-war-on-pollution/

6. Muhammad Wakil Shahzad, Aung Myat, Chun Won Gee and Kim Choon Ng, Bubble-assisted film evaporation correlation for saline water at sub-atmospheric pressures in horizontal-tube evaporator, Applied Thermal Engineering 50 (2013) 670-676.

7. Muhammad Wakil Shahzad, Kim Choon Ng, Kyaw Thu, Bidyut Baran Saha and Won Gee Chun, Multi effect desalination and adsorption desalination (MEDAD): A hybrid desalination method, Applied Thermal Engineering 72 (2014) 289-297

8. Muhammad Wakil Shahzad, Kyaw Thu, Bidyut Baran Saha and Kim Choon Ng, An Emerging Hybrid Multi-Effect Adsorption Desalination System, EVERGREEN Joint Journal of Novel Carbon Resource Sciences \& Green Asia Strategy, 01-02 (2014) 30-36.

9. K. C. Ng, K. Thu, M. W. Shahzad and W. Chun, Progress of adsorption cycle and its hybrids with conventional multi-effect desalination processes, IDA Journal of Desalination and Water Reuse, DOI 10.1179/2051645214Y.0000000020. 
10. Kim Choon Ng, Kyaw Thu, Seung Jin Oh, Li Ang, Muhammad Wakil Shahzad and Azhar Bin Ismail, Recent developments in thermally-driven seawater desalination: Energy efficiency improvement by hybridization of the MED and AD cycles, Desalination 356 (2015) 255-270.

11. Muhammad Wakil Shahzad, Kyaw Thu, Yong-deuk Kim, Kim C Ng, An Experimental Investigation on MEDAD Hybrid Desalination Cycle, Applied Energy 148 (2015) 273-281.

12. Muhammad Wakil Shahzad, Kyaw Thu, Kim Choon $\mathrm{Ng}$ and Chun WonGee, Recent development in thermally activated desalination methods: achieving an energy efficiency less than 2.5 kWh_elec/m3, Desalination and Water Treatment, (2015) 1-10, doi: 10.1080/19443994.2015.1035499.

13. K.C. Ng, K. Thu, B.B. Saha, A. Chakraborty, Study on a waste heat-driven adsorption cooling cum desalination cycle, International Journal of Refrigeration, 35 (2012) 685-693.

14. K. Thu, K.C. Ng, B.B. Saha, A. Chakraborty, S. Koyama, Operational strategy of adsorption desalination systems, International Journal of Heat and Mass Transfer, 52 (2009) 1811-1816.

15. K.C. Ng, X. Wang, Y.S. Lim, B.B. Saha, A. Chakarborty, S. Koyama, A. Akisawa, T. Kashiwagi, Experimental study on performance improvement of a four-bed adsorption chiller by using heat and mass recovery, International Journal of Heat and Mass Transfer, 49 (2006) 33433348 .

16. Chapter 2; Global Desalination Situation, Sabine Lattemann, Maria D. Kennedy, Jan C. Schippers and Gary Amy.

17. http://www.globalwaterintel.com/archive/13/10/general/technology-choice-still-open-yanbu3.html 